\title{
What matters for productive feedback? Disciplinary practices and their relational dynamics
}

Rachelle Esterhazy

Department of Education, University of Oslo, Norway

Corresponding author:

Rachelle Esterhazy

Email: rachelle.esterhazy@iped.uio.no

Phone: +47-22858113

Address: Postboks 1092 Blindern, 0317 Oslo, Norway

ORCHID: 0000-0003-0494-1417

Twitter: Rachelle_Es 


\title{
What matters for productive feedback? Disciplinary practices and their relational dynamics
}

\begin{abstract}
Most research on feedback has paid limited attention to the role of disciplines and their relational dynamics. This article addresses this limitation by offering a conceptualisation of feedback as a relational process that emerges through feedback encounters shaped by the educational and professional practices of the discipline. Using data from a qualitative case study of an undergraduate software engineering course unit, it explores the relational dynamics between different elements of the course and how these dynamics matter for the emergence of productive feedback encounters. The findings show that a wide range of productive feedback encounters occurred between students and both human and material sources throughout the course. Feedback encounters were productive when students had the opportunity to navigate the tools and conventions necessary to participate in the educational practices of the course and, by extension, the discipline's professional practices. Different learning activities were characterised by distinctive relational dynamics that provided various opportunities and constraints for productive feedback encounters to emerge. The findings demonstrate the importance of accounting for disciplinary practices and their relational aspects when designing for learning activities that aim to enable students to productively seek out and engage with feedback.
\end{abstract}

Keywords: Feedback; discipline; social practice; relations; qualitative research

\section{Introduction}

Previous empirical studies on feedback have paid little attention to the role of disciplines and the relational dynamics that characterise different disciplinary course environments (Evans 2013). This is a consequence of the prevalent conceptualisation of feedback as information transmitted from teacher to student (Evans 2013). Several reviews have shown that studies that take this approach typically attempt to identify generalisable characteristics of the feedback receiver, the sender, or the message that can be linked to positive effects on student performance or satisfaction (Evans 2013; Winstone et al. 2016). This indicates that these studies share a normative assumption 
that an ideal way of formulating and delivering feedback comments exists that will lead to student learning, independent of the discipline.

Recent research indicates, however, that disciplines and their specific practices are important for understanding what makes feedback productive (Anderson 2014; Ajjawi et al. 2017). Following this idea, this paper proposes a conceptualisation of feedback that accounts for its situated, relational, and emergent nature. Taking a sociocultural learning perspective (Wertsch 1998; Säljö 2010), feedback is defined as a process that unfolds through social encounters between students, other course participants, and resources. These encounters are only considered to constitute productive feedback if students both make meaning of and act upon knowledge about the quality of their performance and how to improve on the same (Boud and Molloy 2013). Whether and how productive feedback encounters occur is linked to the relational dynamics of a course, which are shaped by a discipline's characteristic social practices.

Conceptually, this study aims to expand our understanding of feedback through a social practice perspective and how such a perspective can illuminate the role of disciplines. Empirically, it explores the relations between different elements of a course and how these elements matter for productive feedback. To that end, a case study of an undergraduate software engineering course is used to address the following question: What relational dynamics in a course are important for productive feedback to emerge?

The article first identifies the limitations of previous studies that regard feedback as a transmission of information, followed by an overview of research exploring relational approaches. The paper then discusses the main principles of sociocultural learning perspectives, which are used as the basis for investigating relational aspects of the feedback process. Finally, it presents the findings from the empirical case study and 
discusses those relational dynamics of the course that are important for feedback to be productive.

\section{Limitations of the transmission approach}

While studies taking the transmission approach to feedback have undoubtedly generated valuable insights into feedback, their findings are often limited by the predominant use of self-reported data that is collected at single moments in time, and that usually omits contextual details (Evans 2013). This approach is linked to several problematic assumptions about feedback. First, feedback is assumed to be a phenomenon that can be broken down into isolated elements that can be studied and eventually optimised for feedback to become productive. The literature includes many contradictory findings about the productiveness of interventions aimed at improving elements of feedback such as delivery modes, timing, or content (Shute 2008). Searching for the most productive feedback in such a reductionist manner might lead to findings of limited value.

Second, feedback is treated as a phenomenon that exists independently of the environment it takes place in and that always functions in similar ways. This implies that feedback can easily be 'added' to any course design. Several researchers have illustrated, however, that context matters for the way students make meaning of feedback (Jansson 2006; Esterhazy and Damşa 2017) or engage in feedback interactions (Ajjawi et al. 2017).

Finally, this perspective views feedback as a unilateral transmission of information from one person to another. Feedback ends with the completion of this transmission, and how learners respond to the information they receive is not generally regarded as problematic. This does not account for this process's relational aspects and how feedback is achieved in interaction between students, teachers, and resources in a 
course. These assumptions are related to the problematic stance that there is an ideal way of implementing feedback that works across all contexts.

Instead of searching for such one-size-fits-all solutions, we should explore alternative conceptualisations of feedback that would provide insights into the relational dynamics between the different elements of a course and how they contribute to productive feedback. The following section examines previous studies that account for the relational aspects of feedback.

\section{The relational aspects of feedback}

Researchers are increasingly problematising transmission approaches to feedback. Boud and Molloy (2013) argue that we should view feedback as a process in which students make meaning of information about their performance, and use this information to enhance the quality of their work. This process unfolds in a relational dynamic between the participants and other elements of the course environment. These environments 'do not come ready made but need to be constructed not only by individual teachers responsible for courses, but also by staff and students working together to construct [a] suitable milieu' (Boud and Molloy 2013, 708).

Similarly, Price et al. $(2013,45)$ argue that feedback is inherently relational and is influenced by 'social structures and discourses that shape the socio-cultural practices of our educational institutions'. This is in line with Anderson and Hounsell (2007) who argue that higher education disciplines comprise certain 'ways of thinking and practicing' and display an 'intricate connection between the content and form of knowledge of a domain' (472). The role of feedback is to 'unpack these practices... and to draw students into deploying them' (Anderson 2014, 138). These studies suggest that feedback is closely intertwined with a given discipline's social practices and that studies of productive feedback should account for these disciplinary practices.

Pre-print version, Assessment \& Evaluation in Higher Education 2018, vol 43, Iss. 8 
While having highlighted the value of a relational view, few of these studies have generated empirical support for the conceptual arguments made. A number of empirical studies have addressed relational aspects of feedback by studying interactions between students and their tutors (Ajjawi and Boud 2017), supervisors (Eriksson and Mäkitalo 2015), or peers (Jansson 2006; Esterhazy and Damşa 2017). As a consequence of their analytical focus on moment-to-moment interactions, however, these studies can only give this much insight into the way feedback is entangled with the wider disciplinary relations of a course. The present study addresses this gap by expanding the unit of analysis to feedback encounters that occur in different learning activities in a course. The next section provides a conceptualisation of productive feedback that accounts for the relational dynamics in a course and the social practices of a given discipline.

\section{Conceptualising productive feedback from a sociocultural perspective}

The use of a sociocultural perspective (Wertsch 1998; Säljö 2010) offers an analytical lens for studying feedback as a relational process that unfolds through different feedback encounters during a higher education course. Productive feedback encounters are characterised by students making meaning of and acting upon knowledge about the quality of their performance and what they can do to improve it. In cases of unproductive (feedback) encounters, students do not achieve this understanding and/or do not engage in any change of their performance. To delineate feedback encounters from other social encounters during a course, the present study focusses only on encounters in which students have produced observable academic performance beforehand (e.g. written text or code). That excludes other types of encounters such as initial instruction or question-and-answer sessions with the teacher before students have produced something. 
Feedback encounters are closely intertwined with the 'relational dynamics' of the course, which refers to the relations between different course elements such as participants, knowledge resources, or materials. Each course has different relational dynamics that are shaped by the social practices of a given discipline. These disciplinary practices are collective ways of doing, which can be divided into educational and professional practices. 'Educational practices' refer to ways of teaching and learning that students and teachers engage in while part of a course in the discipline; 'professional practices' refer to work-related ways of doing that are common among graduates of a given discipline.

Empirically, social practices have both social and material dimensions. They are characterised by specific social conventions and cultural tools that have developed historically and culturally over time (Säljö 2010). 'Social conventions' involve routines of doing certain things and ideas about how responsibilities are distributed among participants. 'Cultural tools' incorporate collective knowledge of the wider domain, which becomes available to the participants through taking these tools into use (Wertsch 1998).

These conventions and tools constitute the structural layer of the disciplinary practices, which provides different opportunities in the course for productive feedback encounters to emerge. Whether and how these opportunities are realised depends on the way participants interpret the conventions and activate the tools in situated enactments. Hence, from a sociocultural perspective, productive feedback can be seen as a collective achievement that is enacted in situ and is shaped by the established conventions and tools of the disciplinary practices. This calls for an analytical approach that allows us to account for both the structural and enactment layers of the practices at play. 


\section{The case study}

A case-study design was used to account for both the structural and enactment layers of the disciplinary practices at the same time. The selected case was a first-year course unit in software development that was part of a software engineering bachelor's degree at a Norwegian university of applied sciences. The case was selected for several reasons. First, the course used a project-based design in which students worked on a group assignment throughout the eighteen-week course length. This design implied that students would generate observable academic performance early on, which was necessary to observe feedback encounters during the course. Second, the case involved a range of participants: two teachers, four advanced bachelor's-degree students as teaching assistants (TAs), and 170 enrolled students. Third, the project work was supported by three kinds of learning activities that provided insights into different relational dynamics: weekly lectures, programming-laboratory sessions (programminglabs), and TA-led coaching sessions. Finally, the course introduced students to one of the key professional practices in the software engineering discipline, thus making it a good case for investigating the role that the discipline's educational and professional practices play for productive feedback.

\section{Methodology}

The collected dataset is part of a larger research project on quality in Norwegian higher education and comprises observations and interviews. Both teachers and two TAs consented to be interviewed at the middle and end of the course. Of the 170 students, five groups with three participants each (total $\mathrm{N}=15$ ) consented to be interviewed at the end of the course. The interviews aimed to elicit experiences with different learning activities; they took around one hour, were conducted in English or Norwegian, and 
transcribed verbatim (156 pages transcripts).

The observation data comprises both observation protocols and video recordings. Across all learning activities, protocols were completed for 11 lectures, 22 coaching sessions, and 6 programming-lab sessions (total of 78 hours). All observations in the following categories were protocolled with time stamp (per minute): student activities, teachers' pedagogical strategies, knowledge resources and technologies, and feedback activities. Video recordings of the five interviewed student groups who also agreed to be recorded during their group work were used as supplementary data (total of 42 hours). Moreover, field notes were taken during all site visits, and relevant course documents were collected. This article's analysis is primarily based on data from the observation protocols and interviews because they provided a comprehensive overview of a) the ways feedback encounters were enacted across the course and b) how participants made meaning of the conventions and tools activated in these encounters.

\section{Analytical strategy}

The analysis followed three steps. First, the focus was directed to the structural layer of the course's educational and professional practices by describing the course's relational dynamics. This step was achieved by using the observation protocols and interviews to create an overview of the course organisation and the different learning activities. Each activity was described according to the activated cultural tools and social conventions. Examples of tools were the materials (e.g. computers and whiteboards) and intellectual resources (e.g. scientific concepts and programming languages) participants engaged with during the activities. Social conventions were identified by describing the distribution of responsibilities among participants as well as any prominent actions and routines involved in the activity. 
Second, the observation protocols were analyzed for instances where students obtained knowledge from human or material resources about their performance and then made changes in response to that knowledge. This generated an overview of different types of feedback encounters that occurred across the different learning activities, and what cultural tools and social conventions were relevant for their enactment.

Finally, out of all observed types of feedback encounters, two examples were selected that had illustrative potential for the key relational dynamics and disciplinary practices that mattered for these encounters to be productive. The examples were selected due to being the types of encounters that most observation and interview material was available on. Each example was analysed in-depth vis-à-vis how the encounter was enacted and what tools and conventions of the learning activity became relevant in their enactment.

\section{Findings}

\section{Educational practices that shaped the learning activities}

This section provides a descriptive account of the structural layer of the educational practices that shaped the different learning activities in the course. It describes the prevalent tools and social conventions that regulate the ways of teaching and learning in each activity. Table 1 provides an overview.

The course organisation was project-based. A project assignment, introduced in the first lecture, required student groups of three to develop a digital board game using programming principles and strategies introduced during the lectures. The assignment was divided into eight sub-assignments that structured the students' work on the source code of the game and the code's technical documentation. The main teacher and an external evaluator graded the final product.

Pre-print version, Assessment \& Evaluation in Higher Education 2018, vol 43, Iss. 8 
Lectures took place once a week in a large lecture hall. This activity was characterised by 'frontal' lecturing, in which the teacher presents the main concepts and strategies relevant to Java software development using PowerPoint presentations or the whiteboard. The main teacher explained that, while students were expected to listen and were allowed to ask questions about the lecture content, they were discouraged from asking questions about their own project work during the lectures; they were instead referred to the other learning activities.

Weekly coaching sessions took place in small lecture halls. These sessions were meant to provide students with tailored and sustained guidance for their projects and the opportunity to ask about topics of interest. Four TAs ran these sessions in parallel. Each class consisted of several student groups that were clustered together according to their previous grades. The TAs used different pedagogical strategies during the coaching sessions, including frontal instruction to elaborate on lecture topics or dialogical instruction-on-demand for students who asked for help with their assignments. Students were expected to attend regularly and to use the sessions to seek help and organise their group work. The activated resources ranged from whiteboards and projectors to a variety of online knowledge resources.

Programming laboratories were held in a large open space where students moved around freely and organised their own work. The TAs visited the labs for two hours twice a week; any groups that needed help with their project could approach them for assistance. Many groups also worked in the same space beyond the scheduled two hours, and the TAs often stayed longer to provide more help.

\section{Professional practices that shaped the learning activities}

In this course, students were not only introduced to educational practices of software engineering, but also to the key professional practice 'software development'. Students

Pre-print version, Assessment \& Evaluation in Higher Education 2018, vol 43, Iss. 8 
were required to write Java code and to engage with the tools and conventions that come with it. Typical tools in this practice include Java compilers, file-management software, and online Java documentation. As is common in professional software development, the students worked collectively on a product over a long timeframe. Their group work was organised by several milestones (sub-assignments) that determined when interim products needed to be generated, tested, and improved until a fully functional version of the application was ready. This iterative, recursive nature of software development had consequences for the way in which learning activities were organised and how feedback opportunities emerged. As such, the various professional and educational practices intersected and shaped one another. The assignment structure and the Java programming language were central tools that provided links between these practices.

\section{Productive feedback encounters across learning activities}

The data yielded a range of different types of feedback encounters in which students made meaning of and acted on knowledge about the quality of their performance and what they could do to improve it. Most of the productive encounters were observed during coaching sessions and programming labs; the lectures rarely constituted arenas for productive feedback. Table 1 provides an overview of the course's learning activities, what cultural tools and social conventions characterised these activities, and what types of productive feedback encounters were observed. The following sections move the focus from the structural to the enactment layer of the practices at play and describe two different types of observed feedback encounters (highlighted in bold in table 1). 
Table 1: Overview of observed learning activities and types of productive feedback encounters (selected examples in bold)

\begin{tabular}{|c|c|c|c|}
\hline $\begin{array}{l}\text { Learning } \\
\text { Activity }\end{array}$ & Cultural tools & Social conventions & Feedback encounters \\
\hline $\begin{array}{l}\text { Lectures } \\
\text { (large lecture } \\
\text { hall) }\end{array}$ & $\begin{array}{l}\text { - Lecture slides } \\
\text { - Concepts and } \\
\text { strategies for Java } \\
\text { programming }\end{array}$ & $\begin{array}{l}\text { - Once/week } \\
\text { - Teachers present contents } \\
\text { at front of hall } \\
\text { - Students listen passively; } \\
\text { discouraged from asking } \\
\text { questions about their } \\
\text { projects }\end{array}$ & $\begin{array}{l}\text { - Students ask about their projects; } \\
\text { teachers direct responses to } \\
\text { whole class or refer to coaching } \\
\text { sessions }\end{array}$ \\
\hline $\begin{array}{l}\text { Coaching } \\
\text { session } \\
\text { (small lecture } \\
\text { hall) }\end{array}$ & $\begin{array}{l}\text { - Assignment task } \\
\text { - Student } \\
\text { projects/Java } \\
\text { coding } \\
\text { - On-screen coding } \\
\text { demonstrations } \\
\text { - Whiteboard } \\
\text { - Online resources } \\
\end{array}$ & $\begin{array}{l}\text { - Once/week } \\
\text { - Classes clustered by } \\
\text { performance level } \\
\text { - TAs as competent peers } \\
\text { who organise activities } \\
\text { - Students work on projects, } \\
\text { seek help actively, co- } \\
\text { organise activity with TAs }\end{array}$ & $\begin{array}{l}\text { - TAs collect common questions } \\
\text { and respond through mini- } \\
\text { lectures to the whole class } \\
\text { - TAs provide individual help to } \\
\text { students } \\
\text { - Students receive help from peers }\end{array}$ \\
\hline $\begin{array}{l}\text { Programming } \\
\text { labs } \\
\text { (open space, } \\
\text { always } \\
\text { accessible) }\end{array}$ & $\begin{array}{l}\text { - Assignment task } \\
\text { - Student } \\
\text { projects/Java } \\
\text { coding } \\
\text { - Online } \\
\text { resources/lecture } \\
\text { slides }\end{array}$ & $\begin{array}{l}\text { - Twice/week scheduled } \\
\text { times when TAs are } \\
\text { available } \\
\text { - TAs and teachers as } \\
\text { knowledge resources who } \\
\text { are available for help } \\
\text { - Students work } \\
\text { independently and move } \\
\text { around freely; some seek } \\
\text { help actively }\end{array}$ & $\begin{array}{l}\text { - Individual help from TA or } \\
\text { teacher when present in lab } \\
\text { - Individual email help from } \\
\text { teachers } \\
\text { - Individual help from peers or } \\
\text { friends outside course } \\
\text { - Error messages during practical } \\
\text { application } \\
\text { - Comparing work with knowledge } \\
\text { from online resources and lecture } \\
\text { slides }\end{array}$ \\
\hline
\end{tabular}

\section{Productive feedback encounter type 1: Mini-lectures during coaching sessions}

This was an example of productive encounters that were typical for coaching sessions.

They qualify as feedback because students obtained knowledge about their performance from the TA and how they could use the lecture content to improve it. They could also apply this knowledge in their projects during these encounters.

During a typical coaching session, ten to fifteen students would sit in groups in a small lecture room. The TAs would start the sessions by presenting topics that they considered relevant according to the questions about the projects the students had raised in the earlier coaching sessions. For example, one TA 'went through the animation sort of thing... because that's a question I've been having a lot over the last one-and-a-half weeks' (TA2). In other cases, these mini-lectures took a more ad-hoc 
format, and TAs would use them to explain issues to the whole class that had emerged from individual students' project-related questions. This often included the TA coding live while projecting the code onto the screen. The students explained that 'when we asked something about the code in [the TA's] classes, he actually put some code examples on the whiteboard and the screen, and he...went through [each] so we could learn how to actually apply it in the programme directly' (Group 4).

\section{Productive feedback encounter type 2: Students seeking help during a} programming lab

This was an example of productive encounters that were typical for the programming lab. They qualify as feedback because individual students gained knowledge about their work and how to improve it by seeking help from TAs during programming labs. This type of encounter unfolded in various patterns. Usually, students were scattered around the open space of the programming lab while working on their assignments. TAs either walked around or sat in the lab attending to their own coursework. When problems arose, students raised their hands or approached the TA to ask questions about their projects. These encounters could be very quick and efficient, as described by a student who 'only needed to just go to [the TA] and just ask something... really quick...just one sentence, and then he'd just answer with like two words, and then I'd understand everything' (Group 4). The encounters could also last for longer times, with rich discussions between students and TAs engaging in problem-solving together. This also meant that students often had to wait, as TAs would still be engaged with other groups. One TA explained that he told 'them where they [were] in the line. First come, first served...And then I [tried] to remember who [was] in the queue'. (TA2). If TAs were unable to help, they often suggested to ask other TAs in the lab (who were assumed to have more expertise in the particular problem) or to email the teacher. 


\section{Unpacking the relations at play during feedback encounters}

This section presents the findings from the in-depth analysis of the two presented types of feedback encounters. The analysis focusses on the relational dynamics that were important for productive feedback encounters to emerge. First, the section presents the cultural tools and how they were used during the different feedback encounters. This is followed by the social conventions that shaped the way the encounters were enacted.

\section{Tools activated during the enactment of feedback encounters}

In both presented encounters a range of cultural tools were activated that incorporated the knowledge and procedures of software engineering's educational and professional practices. Two tools in particular were identified as central for the enactment of feedback encounters: the project assignment and the Java programming language.

The way the project assignment was divided into sub-assignments with different goals was based on the teacher's attempts to provide clear structure and more easily accessible tasks. This decision was influenced by the educational practices the teacher was familiar with. He explained that his experiences convinced him that using a scaffolding structure with frequent feedback opportunities would enable students to accomplish assignments that were initially beyond their abilities. The assignment description was a rich knowledge resource that helped students develop their own code and compare their work against the examples provided in the description. One student explained: 'We solved most of the problems using the task sheets. At least I used them a lot - short codes there - I used them in my codes' (Group 2). The assignment description was activated during several feedback encounters and mediated the immediate interactions (what problem would be attended to) and the students' long-term work (how they planned their projects and divided the tasks). It also entailed the 
assessment criteria that were often activated in the feedback encounters to assess the quality of the students' performance and whether their performance needed improvement. These criteria were both influenced by the conventions derived from educational practices (e.g. all students need to contribute during group work and submit work on time) and from professional practices (e.g. standards for the functionality, aesthetics, and efficiency of the final code).

Java was another central tool that mediated the way in which the feedback encounters unfolded. Java has strong affordances in the form of inscribed rules that must be followed in order to develop functional applications. These affordances mean that the 'power' over judging what is right and wrong in this knowledge domain is not only in the hands of the teacher but ultimately lies in the functionality of the application. The main teacher acknowledged that 'in programming, it's very obvious when you've found a solution, because then it works'. The Java code that needed to be generated to meet the assessment criteria was therefore both the learning object of this course and a tool that mediated the interaction in the feedback encounters. Depending on the code the students were developing and the challenges they met along the way, different resources became relevant in their feedback encounters, and TAs were activated in different ways: for identifying errors, finding and validating knowledge resources, or providing step-bystep instructions.

In both examples, the TAs typically responded to students' questions by demonstrating the use of professional Java tools. This modelling activity is a good example of the role that cultural tools played for the entanglement of educational and professional practices during the feedback encounters. During these demonstrations, the TAs' actions were in part informed by the rules and conventions derived from the educational practice they were familiar with from their own studies (such as vocalising 
the code while typing it), but their actions were also guided by the conventions of professional Java programming, such as checking the code for consistency. At this intersection of educational and professional practice, the modelling during the feedback encounters provided students with access to the actions and conventions relevant to mastering the cultural tools of the profession.

\section{Social conventions that shaped the enactment of feedback encounters}

Feedback encounters were also shaped by the social conventions of the learning activities during which they occurred. Among the conventions that appeared the most relevant were those concerning the time and space of activities, and those concerning the social order and division of responsibilities.

Conventions of when and where different activities typically take place in this particular institution informed the way in which the course was organised. For example, coaching sessions and programming labs were scheduled after the weekly lectures to allow for follow-ups of the lecture contents. Because some TAs were also available outside the assigned lab hours, however, students soon realised that 'if we were stuck in the project, we could just go and ask in the lab. And [at the coaching session], you didn't have to come there because we could just ask any time at the other place' (Group 1). This situation led to a gradual dissolution of the intended course organisation and a change in the way feedback encounters occurred during the different activities. This shows how conventions derived from the common educational practices were renegotiated between the participants over time.

Another example included the different affordances that emerged from the spaces where the learning activities took place. The coaching sessions' small lecture hall, equipped with whiteboard and projector, enabled the TAs to open up individual feedback encounters by directing the whole class's attention from their laptops towards 
the laptop screen projected on the wall. The open space of the programming lab provided fewer opportunities for these whole-class feedback encounters. The size of the labs also required students to be more active in seeking help, as they first had to locate the TA and then wait to ask questions. Students were also more likely to engage in spontaneous feedback encounters with older students who were also working in the lab.

Feedback encounters were also shaped by the social ordering, which was derived from both professional and educational practice. As was common in this study programme, students who had scored similarly in the previous semester were grouped together and assigned to one specific coaching class. Sometimes students would surpass the TAs in their programming skills and felt frustrated that they were unable to find productive help for their work: 'A couple of [the TAs] were very good, but I think about halfway through the course we reached a level where they couldn't always help us' (Group 3). After a while, the original pairing of TAs and students thus developed into an arrangement where more advanced groups would stop attending their assigned coaching sessions and instead engage in feedback encounters with other TAs deemed more skilful.

This situation was related to characteristics specific to the professional practices of software engineering, where competence and authority are linked less to one's formal education level and more to one's practical experience and knowledge. This meant that the students' and TAs' interactions in the feedback encounters were often characterised by a 'flat' hierarchy, where the TAs would join in the problem-solving as equal partners and students would actively co-organise activities. Their division of responsibilities also changed over time. In some cases, students who had initially attended the sessions in a passive manner slowly shifted into different positions of actively engaging the TAs in 
joint problem-solving during feedback encounters or even offering help to other students.

The expectations regarding the students' participation in the educational practices of the course served as a proxy for the expectations they would meet in professional practice. This situation influenced the way in which feedback encounters unfolded, for example by determining when it was appropriate to seek help, how students should interact with one another and with the TA, and what kinds of questions they should ask. For example, one TA explained: 'There's... a million ways to do things in programming, so the good questions are..."Why should I use this and not this?" instead of..."How do I do this?"' (TA2). Similarly, the TAs explained that their approach to providing help was influenced by their experience of how help would be provided in the professional context (i.e. solution-oriented vs self-help-oriented). The main teacher agreed: 'In programming, there isn't one solution to a problem - you have many ways to get there. So we're not necessarily interested in describing the solution to the students but to get the students to reach that solution themselves'.

\section{Discussion}

\section{What relational dynamics matter for productive feedback?}

This study has explored what relational dynamics in a software engineering course were important for the emergence of productive feedback encounters. The analysis yielded rich examples of productive feedback encounters across the different learning activities. In these encounters, students made meaning of and acted upon knowledge about their performance and how to improve the same. Encounters took place both with other participants (e.g. TAs and peers) and with material resources (e.g. software compilers). 
The learning activities differed in their relational dynamics: that is, what conventions were followed, what tools were activated, and how participants related to one another and to these tools. These conventions and tools were derived from established practices in the discipline and constituted a structural layer that framed whether and how feedback encounters emerged. The coaching sessions were organised in a way that afforded the emergence of productive feedback encounters in the form of mini-lectures. The organisation of the programming-lab sessions was more fluid, which required students to become more proactive in seeking feedback. Finally, the frontal teaching during lectures provided the least opportunities for productive feedback encounters to occur. In other words, the relational dynamics of these different learning activities provided varying affordances and constraints for the emergence of productive feedback encounters.

While being framed by the structural aspects of the practice, the actual enactment of feedback encounters was an interactional achievement constituted of the participants' in situ interpretations. The findings showed that students and TAs continuously renegotiated their roles, which were derived both from familiar conventions of educational practices (such as the teacher speaks, and students listen), as well as from the flat-hierarchy conventions common in the collaborative work of professional software engineering. These negotiations were reflected in the TAs' shifting between being teachers or competent peers, while the students shifted between being passive recipients and active knowledge-seekers during the enactment of the feedback encounters. Through these interpretations and negotiations, the course participants made sense of the educational practices and, by extension, of their discipline's professional practices. 
Based on these findings, the answer to the question of what relational dynamics are important for productive feedback encounters is two-fold. First, it mattered how the course was organized and what relations between different course elements were given. Learning activities had to be organised in a way that enough time and space would be available for productive feedback encounters to emerge. Relevant tools and resources had to be made available that had a certain 'feedback potential': that is, resources from which students could obtain relevant knowledge about their performance. Second, the way in which these relations were then interpreted and enacted was an important factor. Even when provided with space, time, and resources for engaging in feedback, students were not guaranteed to take up this opportunity. Productive feedback encounters were most likely to occur within learning activities that allowed for a certain degree of fluidity in interpreting and negotiating the relevant conventions, tools, and roles the course participants could assume, which shows the dynamic and emergent character of feedback.

\section{Contributions}

The findings of this study provide several important contributions to our current understanding of feedback. First, this study contributes an important insight into the way feedback is intertwined with the disciplinary practices of a course. Conventions of the software programming discipline influenced the course organisation and what opportunities were created for feedback encounters: little concrete instruction, project designs that created the need to seek feedback, and spaces that allowed for feedback encounters with TAs. At the same time, the discipline's tools and conventions shaped the way in which feedback encounters were enacted in situ, such as by directing students to online sources or by demonstrating coding. This also meant that students were expected to attempt problem-solving on their own before seeking help and to

Pre-print version, Assessment \& Evaluation in Higher Education 2018, vol 43, Iss. 8 
develop the skills of finding and implementing relevant knowledge from open-access resources. Whether feedback was productive in this course thus depended on disciplinary practices that required students to judge for themselves if they needed to engage in feedback encounters in order to master their assignments.

This finding resonates with the ecological perspective by Ajjawi et al. (2017). They argue that we must account for how feedback is embedded in the wider systems of an institution and discipline in order to understand what makes feedback productive. Related to the first argument is the idea that productive feedback encounters are essential for students to unpack the various ways of thinking and practicing in their discipline (Anderson 2014). The current study, however, has shown that feedback was not merely a pedagogical tool that the teacher added in order to provide students with access to the discipline's ways of thinking and practicing. Instead, the prevailing practices in the course also shaped the teachers' pedagogical approaches and ways of planning for feedback.

Second, the analysis showed that students engaged in productive feedback with both human and material resources, such as the software used to compile their coding. These feedback encounters with material resources were closely intertwined with human feedback interactions, both in initiating encounters (such as when an error message revealed a problem that students needed help with) and structuring encounters (such as when an error message became the shared object of learning). This finding adds to previous studies that have examined the interactional nature of feedback but were limited to interactions with humans (Jansson 2006; Esterhazy and Damşa 2017). These insights suggest that it would be useful to expand our concept of productive feedback to encompass both human and material resources. 
Finally, the insight that feedback encounters are enacted differently each time implies that on each occasion, different elements become important for feedback to be productive. For example, in some encounters the temporal-spatial characteristics of the activity are relevant, while in others the relation between the students' and TAs' levels of competence mattered. In that regard, this study contributes to research focussed on the moment-to-moment interactions during feedback encounters (Jansson 2006; Ajjawi and Boud 2017) by showing that the relational dynamics of the course provided the frames in which these interactions unfolded.

\section{Implications and limitations}

This study has both methodological and practical implications. It shows that using a sociocultural and practice-oriented approach can overcome the limitations of analyses focussed only on formal teacher-driven feedback. This approach allows for an understanding of any encounters that contribute to students' knowledge about the quality of their work (and how to improve it) as feedback, even if the students themselves do not identify such encounters as feedback.

Looking at feedback from a social practice perspective leads to several new questions. If productive feedback emerges as being embedded in social practices, how can the established educational and professional practices of our disciplines be taken into account when designing and implementing feedback in a course? And how can practices that afford productive feedback be made sustainable? Both questions are related to the key assumption that each instantiation of a practice will shape the way the practice will be enacted in the future. That means that each time participants and resources meet in a feedback encounter, conventions are reinterpreted and tools are used in slightly different ways, thereby contributing to the way the practice will be enacted in the future (Säljö 2005).

Pre-print version, Assessment \& Evaluation in Higher Education 2018, vol 43, Iss. 8 
These insights have several practical implications. Course designers should organise learning activities that will provide opportunities for feedback encounters in which students can make meaning of and act upon knowledge about their current performance in a timely fashion. Students should be required to generate academic products early on in the process, which will then create the need to seek and use feedback in order to pass the assessment. Both students and teachers need to learn to recognise the integrated, often material, feedback resources that students encounter in higher education settings. Students who engage in feedback encounters of various types are more likely to develop feedback literacy and to actively seek and engage with feedback in the future. This situation will help to turn productive feedback processes into an institutionalised element of the educational practices in the study programme, thus making them more sustainable (Boud and Molloy 2013). Teachers can support this process by (1) designing activities where students can easily seek help, (2) making relevant knowledge resources available, and (3) explicitly stating how these items can be accessed and used. Students should also be informed about the roles they are to assume while giving them enough flexibility to shift into the varying roles that will be most productive at any given time. These practical implications contribute further details to Boud and Molloy's (2013) general recommendation that a suitable milieu needs to be constructed if feedback is to be productive.

Some limitations follow with the single case study research design. Other relevant findings might have emerged if more cases had been included. The primary aim of this study, however, was to study the general principle of how feedback is intertwined with practices of any given discipline, rather than investigating what makes feedback productive in software engineering specifically. The sociocultural framing of this study suggests that the empirically identified dynamics between feedback and disciplinary 
practices can be generalized on a theoretical basis and would therefore be expected to be present also in other disciplinary contexts (Eisenhart 2009).

Another limitation of the dataset emerged from the fact that only activities that took place in organised course settings were observed. While feedback encounters may have taken place outside these activities, however, the interview data suggested that most of the productive feedback occurred during the course activities.

\section{Concluding remarks}

This study has provided empirical insights into the relational dynamics of feedback in higher education. It has shown how productive feedback is a dynamic and emergent process that is accomplished through social encounters between students, teachers, and relevant resources in the course. How productive feedback emerges depends on the relations between the elements of the course and the disciplinary practices that shape them. The study makes a case for studying feedback from a relational perspective that accounts for the complex and dynamic environment that characterises higher education. It also highlights the importance for teachers to account for disciplinary practices and their relational aspects when designing for learning activities aimed at enabling students to productively seek out and engage with feedback. This implies increased awareness on the teachers' side for the relevant tools and conventions of their discipline and how different learning activities provide different opportunities for feedback encounters. What it takes for teachers to develop such awareness and to plan for productive feedback in their own disciplinary contexts are questions that open up interesting avenues for further research. 
Funding details: This work was supported by the Norwegian Research Council under FINNUT Grant Nr. 237960.

Disclosure statement: No potential conflict of interest was reported by the authors.

\section{Acknowledgements}

This study was carried out in the context of the QNHE project (Quality of Norwegian Higher Education; www.qnhe.no). I am grateful to the participants in the study for providing insight into their work. Special thanks go also to Monika Nerland, Crina Damsa and the colleagues at CRADLE for their valuable comments on earlier versions of the manuscript.

\section{References}

Ajjawi, R., and D. Boud. 2017. 'Researching Feedback Dialogue: An Interactional Analysis Approach'. Assessment \& Evaluation in Higher Education 42 (2):25265.

Ajjawi, R., E. Molloy, M. Bearman, and C. E. Rees. 2017. 'Contextual Influences on Feedback Practices: An Ecological Perspective'. In Scaling Up Assessment for Learning in Higher Education, edited by D. Carless, S. Bridges, C. KY Chan, and R. Glofcheski, 129-43. Singapore: Springer.

Anderson, C. 2014. 'Only Connect? Communicating Meaning through Feedback'. In Advances and Innovations in University Assessment and Feedback, edited by C.

Kreber, C. Anderson, N. Entwistle, and J. McArthur, 131-51. Edinburgh: Edinburgh University Press.

Anderson, C., and D. Hounsell. 2007. 'Knowledge Practices: "Doing the Subject" in Undergraduate Courses'. The Curriculum Journal 18 (4):463-78.

Boud, D., and E. Molloy. 2013. 'Rethinking Models of Feedback for Learning: The Challenge of Design'. Assessment \& Evaluation in Higher Education 38 (6):698-712. 
Eisenhart, M. 2009. 'Generalization from Qualitative Inquiry'. In Generalizing from Educational Research: Beyond Qualitative and Quantitative Polarization, edited by K. Ercikan and W.M. Roth, 51-66. New York: Routledge.

Eriksson, A. M., and Å. Mäkitalo. 2015. 'Supervision at the Outline Stage: Introducing and Encountering Issues of Sustainable Development through Academic Writing Assignments'. Text \& Talk 35 (2):123-53.

Esterhazy, R., and C. Damşa. 2017. 'Unpacking the Feedback Process: An Analysis of Undergraduate Students' Interactional Meaning-Making of Feedback Comments'. Studies in Higher Education 0 (0):1-15.

Evans, C. 2013. 'Making Sense of Assessment Feedback in Higher Education'. Review of Educational Research 83 (1):70-120.

Jansson, G. 2006. 'Recontextualisation Processes as Sense-making Practice in StudentWriters' Collaborative Dialogue'. Studies in Higher Education 31 (6):667-88.

Price, M., K. Handley, B. O’Donovan, C. Rust, and J. Millar. 2013. 'Assessment Feedback: An Agenda for Change'. In Reconceptualising Feedback in Higher Education: Developing Dialogue with Students, edited by M. Price, S. Merry, and D. Carless, 41-53. London: Routledge.

Säljö, R. 2005. Lärande Och Kulturella Redskap: Om Lärprocesser Och Det Kollektiva Minnet. (Learners and Cultural Tools: On Learning processes and the Collective Mind) Stockholm: Norstedts akademiska förlag.

— 2010. 'Learning in a Sociocultural Perspective'. In International Encyclopedia of Education, 3rd ed., edited by P. Peterson, E. Baker, and B. McGaw, 498-502. Oxford: Elsevier.

Shute, V. J. 2008. 'Focus on Formative Feedback'. Review of Educational Research 78 (1):153-89.

Wertsch, J.V. 1998. Mind as Action. New York: Oxford University Press.

Winstone, N. E., R. A. Nash, M. Parker, and J. Rowntree. 2016. 'Supporting Learners' Agentic Engagement with Feedback: A Systematic Review and a Taxonomy of Recipience Processes'. Educational Psychologist 52 (1):17-37. 